\title{
Pantoprazole, an FDA-approved proton-pump inhibitor, suppresses colorectal cancer growth by targeting T-cell- originated protein kinase
}

\author{
Xiaoyu Zeng ${ }^{1, *}$, Lin Liu ${ }^{1, *}$, Mengzhu Zheng ${ }^{2,}$, , Huimin Sun ${ }^{3}$, Juanjuan Xiao ${ }^{1}$, Tao \\ Lu $^{1}$, Guangqian Huang ${ }^{1}$, Pianpian Chen ${ }^{4}$, Jianmin Zhang ${ }^{1}$, Feng Zhu ${ }^{1}$, Hua $\mathbf{L i}^{2,5}$, \\ Qiuhong Duan ${ }^{1}$ \\ ${ }^{1}$ Department of Biochemistry and Molecular Biology, School of Basic Medicine, Huazhong University of Science and Technology, \\ Wuhan, Hubei, 430030, PR China \\ ${ }^{2}$ School of Pharmacy, Tongji Medical College, Huazhong University of Science and Technology, Wuhan, Hubei, 430030, PR \\ China \\ ${ }^{3}$ Department of Urology, Xijing Hospital, the Fourth Military Medical University, Xi'an, Shaanxi, 710032, PR China \\ ${ }^{4}$ Department of Neurobiology, School of Basic Medicine, Huazhong University of Science and Technology, Wuhan, Hubei, \\ 430030, PR China \\ ${ }^{5}$ School of Traditional Chinese Materia Medica, Shenyang Pharmaceutical University, Shenyang, Liaoning, 110016, PR China \\ *These authors have contributed equally to this work \\ Correspondence to: Feng Zhu, e-mail: fengzhu@hust.edu.cn \\ Hua Li, e-mail: li_hua@hust.edu.cn \\ Qiuhong Duan, e-mail: duanqhwz@hust.edu.cn
}

Keywords: pantoprazole, PPI, TOPK, cell transformation, colon carcinoma

Received: November 11,2015 Accepted: February 25, $2016 \quad$ Published: March 8, 2016

\section{ABSTRACT}

T-cell-originated protein kinase (TOPK) is highly expressed in several cancer cells and promotes tumorigenesis and progression, and therefore, it is an important target for drug treatment of tumor. Pantoprazole (PPZ) was identified to be a TOPK inhibitor from FDA-approved drug database by structure based virtual ligand screening. Herein, the data indicated that pantoprazole inhibited TOPK activities by directly binding with TOPK in vitro and in vivo. EX vivo studies showed that pantoprazole inhibited TOPK activities in JB6 Cl41 cells and HCT 116 colorectal cancer cells. Moreover, knockdown of TOPK in HCT 116 cells decreased their sensitivities to pantoprazole. Results of an in vivo study demonstrated that i.p. injection of pantoprazole in HCT 116 colon tumorbearing mice effectively suppressed cancer growth. The TOPK downstream signaling molecule phospho-histone $\mathrm{H3}$ in tumor tissues was also decreased after pantoprazole treatment. In short, pantoprazole can suppress growth of colorectal cancer cells as a TOPK inhibitor both in vitro and in vivo.

\section{INTRODUCTION}

Recently, cancer drug development has shifted from traditional cytotoxic drugs to agents that target the special molecular pathology, driving the progression of 'personalized' medicine [1]. The typical representative for this alternative approach for the treatment of cancer is imatinib, a BCR-Abl tyrosine kinase inhibitor, which left a deep impression on people [2]. For targeted cancer therapy, small-molecule inhibitors fall broadly into four categories. They are kinase inhibitors, chaperone inhibitors, histone deacetylase inhibitors and inhibitors of protein-protein interactions. In this study, we devote ourselves to studying T-cell-originated protein kinase (TOPK) inhibitors.

TOPK is a serine-threonine kinase, a member of MAPKK family. TOPK was confirmed to be highly expressed in multiple types of cancers and associated with poor prognosis, such as lymphoma, leukemia, melanoma, colorectal, breast and lung cancers, and cholangiocarcinoma [3-10]. Also, TOPK plays an important role in tumor development and progression [1113]. Above all, TOPK exhibits high expression levels in cancer tissues but only low expression levels in normal 
Table 1: Binding affinity and inhibitory activities of screening hits

\begin{tabular}{|c|c|c|c|}
\hline \multirow[t]{2}{*}{ Compound } & ICM docking mfscore ${ }^{a}$ & $\begin{array}{c}\text { Dissociation constant with } \\
\text { TOPK }\end{array}$ & $\begin{array}{c}\text { Inhibitory activities against } \\
\text { HCT116 cells }\end{array}$ \\
\hline & (kcal/mol) & $K d^{b}(\mu M)$ & IC50 $(\mu \mathrm{M})$ \\
\hline Pantoprazole & -164 & $24.2 \pm 2.3$ & 185.8 \\
\hline Sulfasalazine & -142 & $339.0 \pm 7.7$ & $n . i^{c}$ \\
\hline Benserazide & -86.04 & $477.0 \pm 19.9$ & $n . i^{c}$ \\
\hline Practolol & -84.38 & $226.0 \pm 29.5$ & $n . i^{c}$ \\
\hline HI-TOPK-032 & -139.5 & $327.0 \pm 62.7$ & n.p ${ }^{d}$ \\
\hline
\end{tabular}

${ }^{a}$ Docking score/interaction potential of compounds with TOPK ( $\left.\mathrm{kcal} / \mathrm{mol}\right)$.

${ }^{b}$ The $\mathrm{Kd}$ value is automatic calculated by the curve fitting, and presents as means $\pm \mathrm{SD}$.

${ }^{c} n$.i. is no inhibition detected in the experiments.

${ }^{\mathrm{d}}$ n.p. is not performed in this study.

tissues [11]. These suggest that TOPK might be an excellent drug target for cancer chemotherapy. However, there is still no TOPK inhibitor in clinic use. There are two TOPK inhibitors, HI-TOPK-032 [14] and OTS964 [15], reported in 2012 and 2014 respectively. However, because of the solubility and toxicity of the two compounds, there would be a long way for them to be used clinically.

In this study, structure based virtual ligand screening method was employed to screen the FDA-approved drug database and pantoprazole (PPZ) was identified as a TOPK inhibitor.

\section{RESULTS}

\section{Virtual ligand screening identifies the binding of pantoprazole to TOPK}

Due to the absence of the crystal structure of TOPK or its closely related homologue, a homology model of human TOPK was constructed by using the X-ray structure of the IRAK-4 kinase (PDB code: 2NRU) as the template, which has $29 \%$ of sequence identities to the human TOPK and $2.0 \AA$ resolution of the structure. The model generated was used for subsequent molecular docking. In the docking calculation, the binding site was assigned across the entire structure of TOPK, and was determined with the lowest-energy and the most favorable orientation of the ligand. Over 2924 approved drugs and nutraceuticals from ZINC Drug Database were screened in silico. Four compounds (Table 1) exhibiting significant mfScores (more negative better) and docking well into the active site of the enzyme were selected for further biological evaluation. The mfScore here represents the independent score of the strength of inhibitor-enzyme interaction. Pantoprazole was shown to have the best docking score. From the generated docking model, hydrogen bonds were predicted between the sulphone oxygen of pantoprazole with K213, phenyl ether oxygen with Y264, respectively. Also, the pyridine ring of the compound may form the $\pi-\pi$ stacking interaction of the benzene ring of F197.

To validate the finding of the virtual ligand screening, we employed microscale thermophoresis method (MST) to assay the binding affinity between the compounds and TOPK. This technology detected fluorescent changes of molecules during thermophoresis, to quantify protein-protein interactions or proteinsmall molecule interactions with high sensitivity and low sample cost. Among four compounds assayed, pantoprazole exhibited the lowest equilibrium dissociation constant (Kd) of $24.2 \pm 2.32 \mu \mathrm{M}$ (Table 1, Figure 1A, 1B, Supplementary Figure 1A, 1B, 1C), which meant the strongest binding. The binding of pantoprazole was also stronger than that of HI-TOPK-032, a previously reported TOPK inhibitor (Table 1, Figure 1C).

\section{Pantoprazole inhibits EGF-induced anchorage- independent growth of JB6 Cl41 cells}

The chemical structure of pantoprazole is shown in Figure 2A. To determine the cytotoxicity of pantoprazole, different concentrations of the drug were used to treat JB6 C141 mouse epidermal cells (JB6 C141 cells) for 24 h. Cytotoxicity was measured by MTS assay and the results indicated that pantoprazole had no cytotoxicity toward JB6 Cl41 cells up to $100 \mu \mathrm{M}$ at $24 \mathrm{~h}$ (Figure 2B). Next, we investigated whether pantoprazole had an effect on anchorage-independent growth of JB6 Cl41 cells. Anchorage-independent growth ability is a hallmark of in vitro transformed cells and cancer cells. Our results revealed that JB6 $\mathrm{Cl} 41$ cells treated with pantoprazole formed fewer colonies compared with the control cells treated with only epidermal growth factor (EGF) (Figure 2C). These results showed that pantoprazole could attenuate EGF-induced anchorage-independent cell growth and was not cytotoxic in clinically relevant doses. 

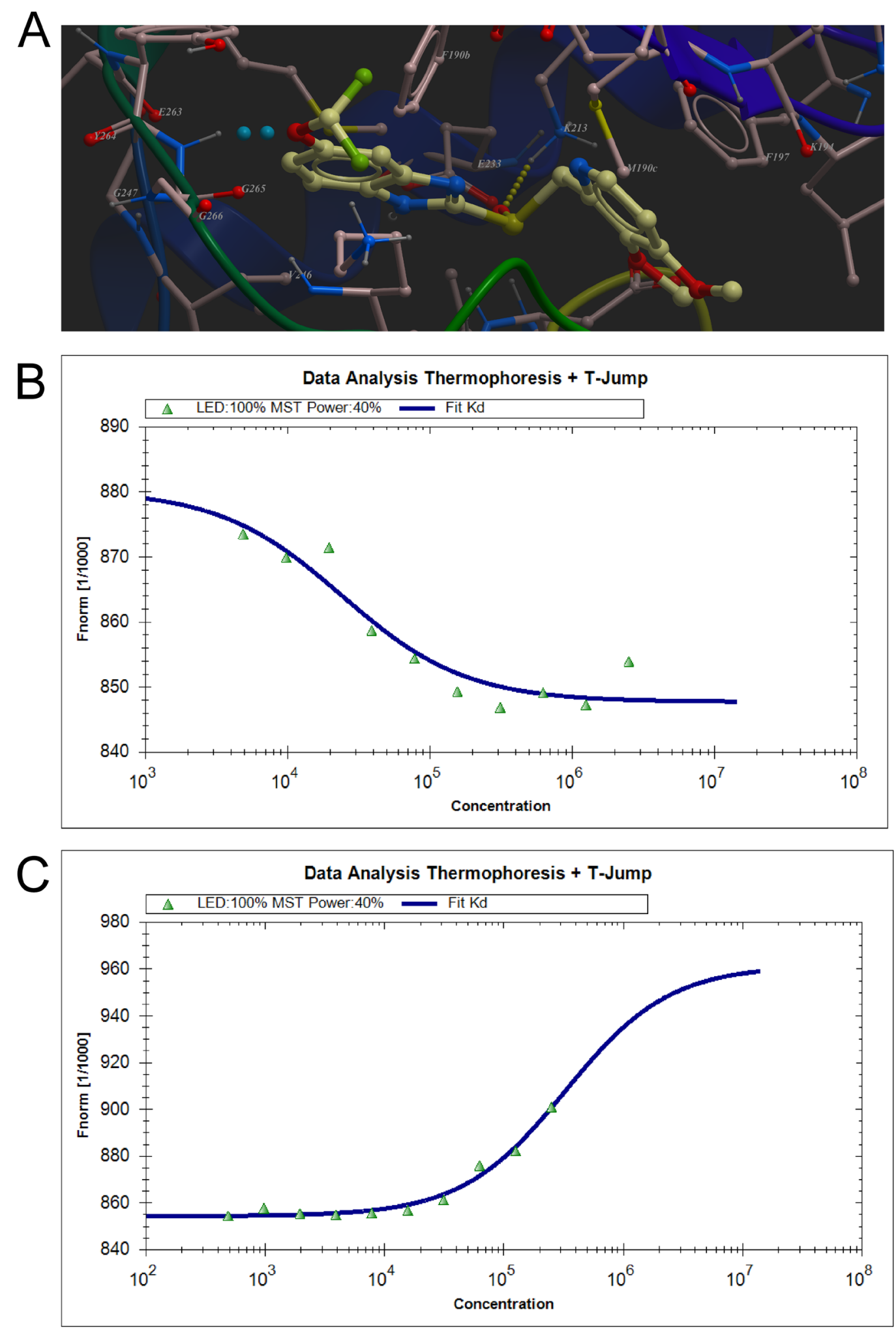

Figure 1: Virtual ligand screening identifies the binding of pantoprazole to TOPK. A. Low-energy binding conformations of pantoprazole bound to TOPK generated by virtual ligand docking. The structure of TOPK was generated by homology modeling by using the structure of RIP3 kinase domain (PDB code: 4m66) as the template, and depicted in ribbon form. Pantoprazole depicted as the balland-stick model showing carbon (yellow), hydrogen (grey), oxygen (red), nitrogen (blue), and fluoride (green) atoms. Hydrogen bonds are represented in dotted lines. B. Measurement of affinity between Pantoprazole and TOPK by MST in standard treated capillaries, and the resulting binding curve was shown. From the resulting binding curve, with a Kd of $24.2 \pm 2.32 \mu \mathrm{M}$. C. The binding curve of HI-TOPK-032 and TOPK from MST, with a Kd of $327 \pm 63.7 \mu \mathrm{M}$. 


\section{Pantoprazole suppresses TOPK activity in vitro and in JB6 Cl41 cells}

Based on our previous data showing that pantoprazole directly binds with TOPK, we adopted an in vitro kinase assay with histone $\mathrm{H} 3$ as substrate to further confirm that pantoprazole inhibits TOPK activities. The results showed that phosphorylation of histone $\mathrm{H} 3$ (Ser10) was substantially attenuated in a dose-dependent manner after treatment with pantoprazole (Figure 3A). In addition, we examined whether pantoprazole could suppress TOPK activities in JB6 Cl41 cells. Data indicated that phosphorylation of histone H3 (Ser10) was lessened by treatment with pantoprazole in a time-dependent (Figure 3B) and dose-dependent manner (Figure 3C).

\section{Pantoprazole inhibits anchorage-independent growth of colorectal cancer cells}

Previous studies suggested that TOPK is highly activated in human colon cancer. We attempted to determine whether pantoprazole could affect anchorage-independent growth of colon cancer cells. We used three colon cancer cell lines HCT 116, SW480 and WiDr with high, middle and low expression level of TOPK, respectively (Figure 4A). To determine the cytotoxicity of pantoprazole,

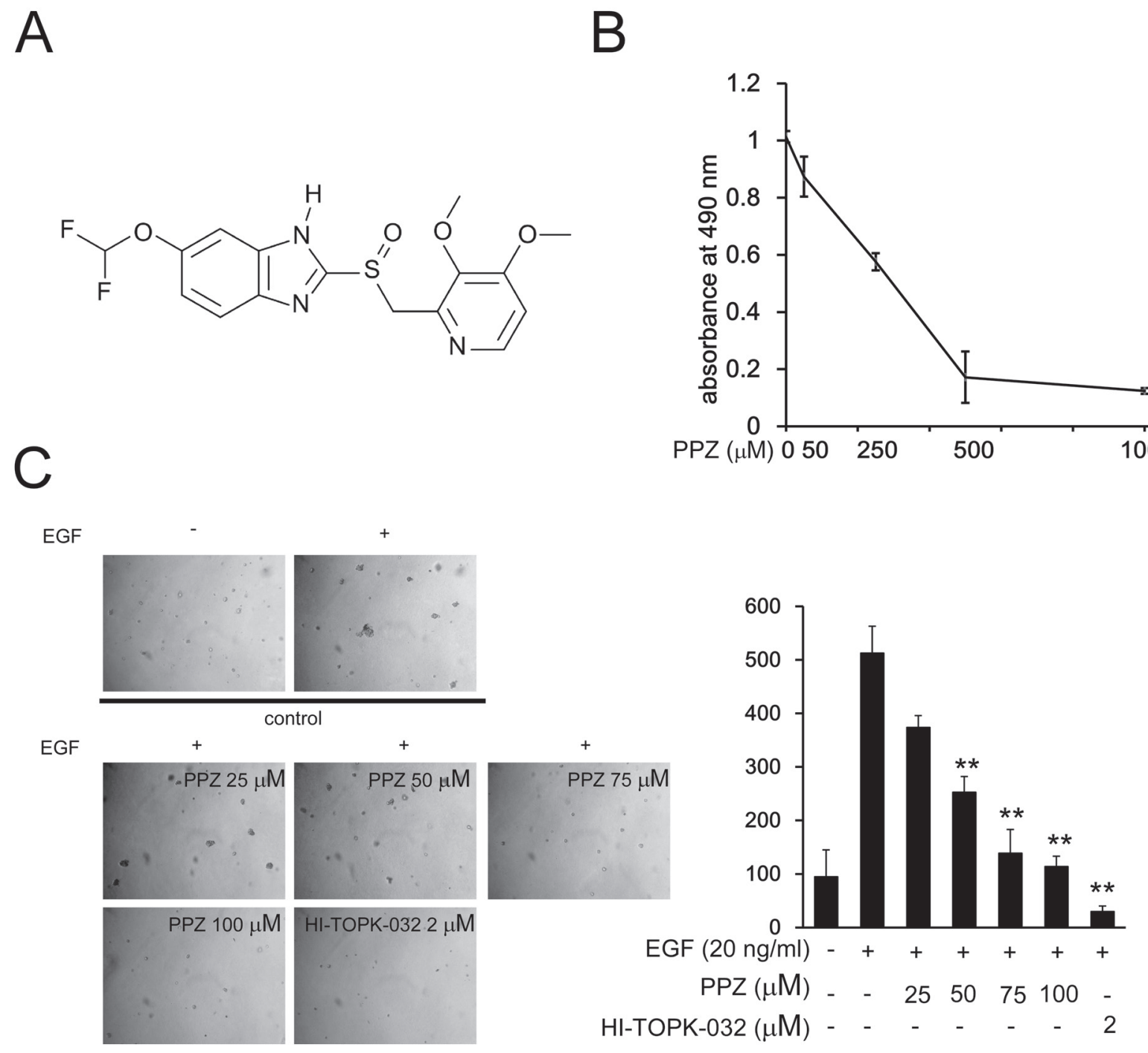

Figure 2: Pantoprazole inhibits EGF-induced anchorage-independent growth of JB6 Cl41 cells. A. The chemical structure of pantoprazole. B. Cytotoxic effects of pantoprazole on mouse epidermal JB6 Cl41 cells. An MTS assay was used after treatment of cells with pantoprazole for 24h. C. Pantoprazole inhibits EGF-induced anchorage-independent growth of JB6 Cl41 cells. JB6 Cl41 cells $\left(8 \times 10^{3}\right)$ were exposed to EGF $(10 \mathrm{ng} / \mathrm{ml})$ and treated with pantoprazole $(0-50 \mu \mathrm{M})$ in $1 \mathrm{~mL}$ of $0.3 \%$ Basal Medium Eagle (BME) agar containing $10 \% \mathrm{FBS}, 2 \mathrm{mM} \mathrm{L}$-glutamine, and $25 \mu \mathrm{M}$ gentamicin. The cultures were maintained at $37^{\circ} \mathrm{C}$, in a $5 \% \mathrm{CO}_{2}$ incubator for 14 days, and the cell's colonies were scored using a microscope Motic AE 20 (China) and the Motic Image Plus computer program. The numbers of colonies represent the whole culture well colonies. Data are shown as mean \pm standard deviation from triplicate experiments. The $\mathrm{P}$ values indicate a significant inhibition by pantoprazole in colony formation $(* P<0.05 ; * * P<0.01)$. 

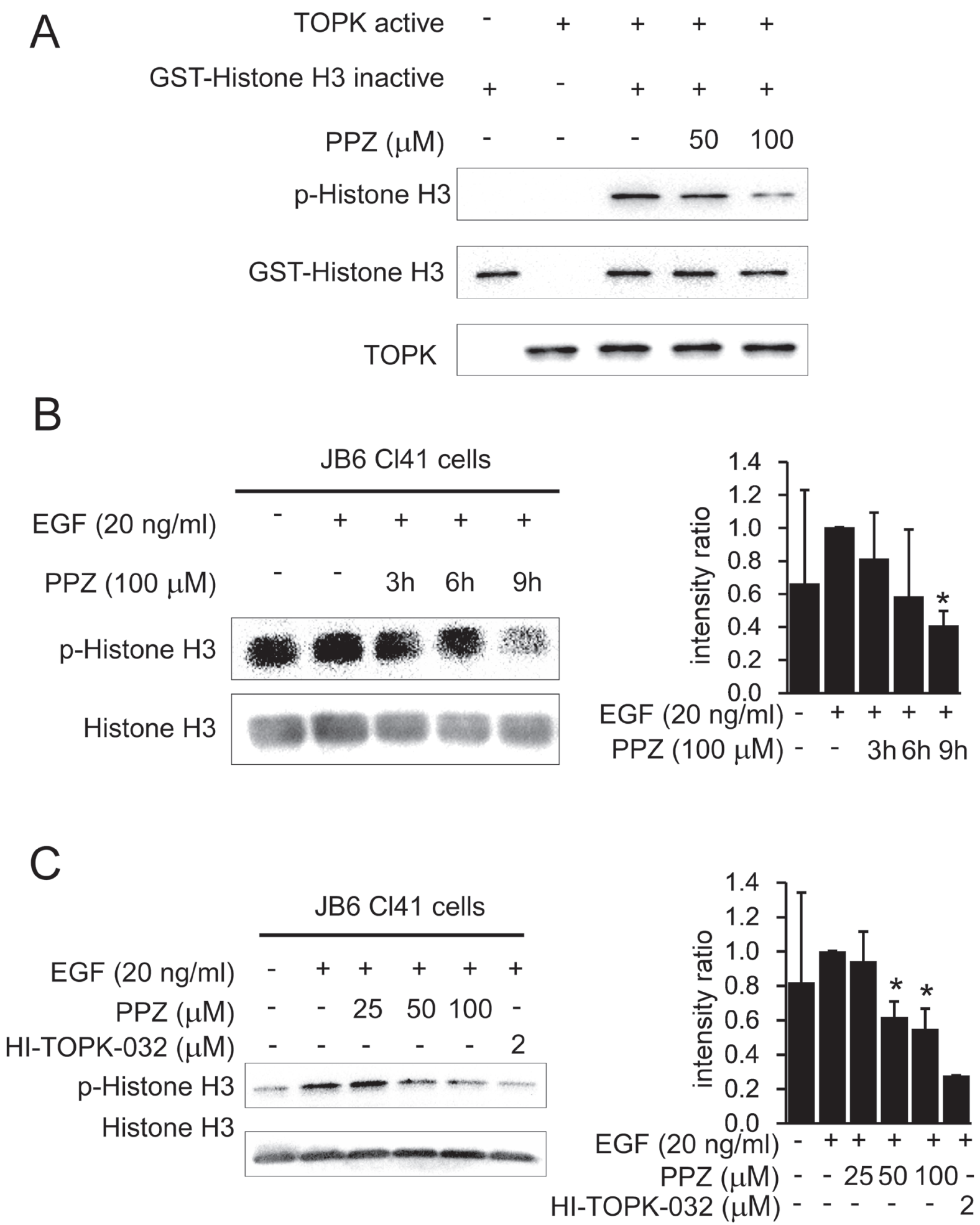

Figure 3: Pantoprazole suppresses TOPK activity in vitro and in JB6 Cl41 cells. A. Pantoprazole inhibits TOPK activity in vitro. The inhibitory effect of pantoprazole on TOPK was determined by an in vitro kinase assay as described in section 'Materials and methods'. The expression level of phosphorylated histone H3 (Ser10) was confirmed by western blot analysis using an antibody against phosphorylated histone H3. GST-histone H3 was used as a loading control. Data are representatives of results from triplicate experiments. B. Pantoprazole inhibits TOPK activity JB6 Cl41 cells. Cells were treated in the presence or absence of $100 \mu \mathrm{M}$ pantoprazole for various times, then treated with $20 \mathrm{ng} / \mathrm{ml}$ EGF for 30 minutes, histones were extracted from cells, electrophoresed on 15\% SDS-PAGE gels, total histone $\mathrm{H} 3$ and phosphorylated histone $\mathrm{H} 3$ proteins were detected by western blot using specific antibodies. Data are representatives of results from triplicate experiments and the intensity ratio of p-Histone $\mathrm{H} 3$ to total Histone $\mathrm{H} 3$ was calculated by an image $\mathbf{J}$ software. $\mathbf{C}$. Different concentrations of pantoprazole were incubated with JB6 cells for $9 \mathrm{~h}$ and $2 \mu \mathrm{M}$ of HI-TOPK-032 was a positive control. 
different concentrations of the drug were used to treat colon cancer cell lines HCT 116, SW480 and WiDr for 48h, respectively (Figure 4B). Cytotoxicity was measured by MTS assay and the results indicated that pantoprazole had different cytotoxicities toward different colon cancer cells. HCT 116 cells with high level TOPK were more sensitive to pantoprazole (Figure 4E). The cells were maintained with different concentrations of pantoprazole and colony numbers were counted after culturing for 7-14 days. The results showed that pantoprazole at $25,50,75,100 \mu \mathrm{M}$ and HI-TOPK-032 at $2 \mu \mathrm{M}$ inhibited colony formation of WiDr on $0,8,5,15$ and 24\%; SW480 cells on 27, 27, 50, 62 and $77 \%$ and HCT 116 on 20, 40, 51, 67 and 75\% respectively, compared with the non-treated cells (Figure 4C-4E). Overall, our results suggested that inhibitory effect of pantoprazole on colony formation was significant in HCT 116 cells with a high expression level of TOPK.

\section{Knocking down TOPK attenuates the inhibitory effect of colon cancer cell growth by pantoprazole}

In addition, to investigate whether the effects of pantoprazole are mediated directly through TOPK, we compared the effects of HCT 116 cells transfected with a shMOCK or shTOPK plasmid (\#1-\#5) (Figure 5A). Pantoprazole suppressed anchorage-independent growth in shMOCK cells but had less effects in shTOPK cells (Figure 5B). Western blot results showed that TOPK-mediated phosphorylation of histone $\mathrm{H} 3$ (Ser10) was substantially decreased time dependently with pantoprazole treatment (Figure 5C). These results suggested that TOPK is a direct target for pantoprazole to suppress colon cancer cell growth.

\section{Pantoprazole suppresses tumor growth by inhibiting TOPK activity in vivo}

Based on our previous data, the next step was to determine whether pantoprazole could suppress tumor growth in vivo. After injecting HCT 116 cells into nude mice, and then the mice were divided into two matched groups. Treatment was started after two days of cells injection. The first measurable tumors were observed on day 11 . The results indicated that tumors treated with $100 \mathrm{mg} / \mathrm{kg}$ pantoprazole grew significantly more slowly and the size of tumors was smaller compared with the vehicle group (Figure 6A). On day 19, the average tumor volume per mouse treated with $100 \mathrm{mg} / \mathrm{kg}$ pantoprazole was $111 \mathrm{~mm}^{3}$ while that was $285 \mathrm{~mm}^{3}$ in the vehicle group (Figure 6B). The average body weights of either group were similar throughout the study (Figure 6C), which indicated that the dose of pantoprazole used for the experiment had no toxicity to the mice. To further determine whether the antitumor effect of pantoprazole was associated with its inhibition of TOPK activities, tumor extracts from either group were prepared and analyzed for phosphorylation of histone H3. The results of immunohistochemistry analysis showed that expression of phosphorylated histone $\mathrm{H} 3$ was substantially decreased in the pantoprazole-treated group compared with the vehicle group (Figure 6D). Overall, our results indicated that pantoprazole suppressed tumor growth by inhibiting TOPK activities in vivo.

\section{DISCUSSION}

Pantoprazole, an FDA-approved proton-pump inhibitor, herein is reported to exert antitumor activities by targeting TOPK. TOPK inhibitors which could benefit $30-40 \%$ of CRC patients might represent a new avenue of investigation for targeted therapy [16]. Therefore, it is important to find a TOPK inhibitor that could be put into clinical use as soon as possible.

In the process of new drug development, it is difficult to move from preclinical screening to clinical trials for its high cost and low success rate. Drug repurposing is the process of exploiting new indications for existing drugs [17]. The supposition of drug repositioning is that these types of drugs are probably to enter clinical trials faster and less expensively, because of verified bioavailability and compatibility. Thus, interests in this strategy have been growing fast in recent years. For example, Orlistat, an FDA-approved anti-obesity drug, was found to inhibit endothelial cell proliferation and angiogenesis by suppressing several new targets. As a result, this compound, as well as other orlistat like analogues, has been proposed as potential anticancer drugs [18].

Structure based virtual ligand screening has emerged as an effective way to find lead compounds for given targets in a high-throughput manner with low cost, while avoiding purchasing thousands of compounds before obtaining hits [19-22]. The combination of structure-based virtual ligand screening and drug repositioning thus represents an efficient method to find new drugs. In order to find out new inhibitors of TOPK that might be applied clinically immediately, we performed structure based virtual ligand screening against ZINC Drug Database by a homology model of human TOPK. Over 2924 approved drugs and nutraceuticals from ZINC Drug Database were screened and four drugs were found to be potential inhibitors. We further confirmed that pantoprazole, a FDA-approved protonpump inhibitor (PPI), was an effective TOPK inhibitor. Pantoprazole bound specifically with TOPK and inhibited its activities. The binding between pantoprazole and TOPK was even stronger than that with the known TOPK inhibitor HI-TOPK-032. Compared with HI-TOPK-032 and OTS964, pantoprazole has much lower cytotoxicities (Supplementary Figure 2). All these tend to imply that pantoprazole is at least a good lead compound for designing novel TOPK inhibitors. 


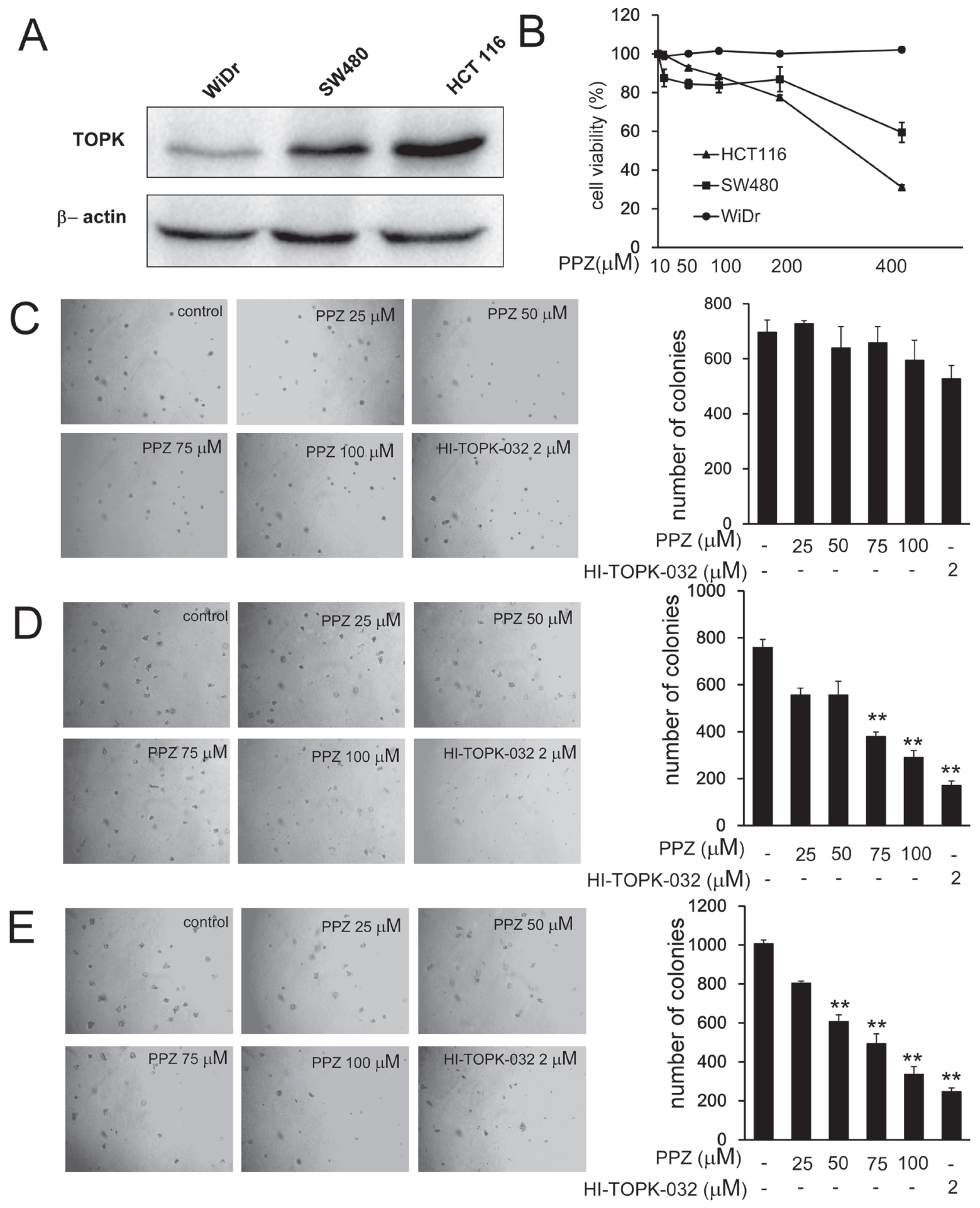

Figure 4: Pantoprazole inhibits anchorage-independent growth of colorectal cancer cells. A. Expression of TOPK in colon cancer cell lines WiDr, SW480, and HCT 116. B. Different concentrations of pantoprazole were used to treat colon cancer cell lines WiDr, SW480, and HCT 116 for 48h respectively. Cytotoxicity was measured by MTS assay. C-E. The effect of pantoprazole on anchorageindependent growth of colon carcinoma cell lines with different level of TOPK expression, including WiDr cells (C), SW480cells (D), and HCT 116 cells (E). WiDr cells, SW480cells, and HCT 116 cells $\left(8 \times 10^{3}\right.$ cells $\left./ \mathrm{mL}\right)$ were treated with pantoprazole $(0-100 \mu \mathrm{M})$ in $1 \mathrm{~mL}$ of $0.3 \%$ Basal Medium Eagle (BME) agar containing 10\% FBS, $2 \mathrm{mM} \mathrm{L}$-glutamine, and $25 \mu \mathrm{g} / \mathrm{mL}$ gentamicin. The cultures were maintained at $37^{\circ} \mathrm{C}$, in a $5 \% \mathrm{CO}_{2}$ incubator for 14 days, and the cell's colonies were scored using a microscope Motic AE 20 (China) and the Motic Image Plus computer program. The numbers of colonies represent the whole culture well colonies. Data are shown as means \pm standard deviation of values from three independent experiments and the asterisk indicates a significant $\left({ }^{*} p<0.05,{ }^{* *} p<0.01,{ }^{* * *} p<0.001\right)$ decrease in colony formation in cells treated with pantoprazole compared with the PBS-treated group. 
A
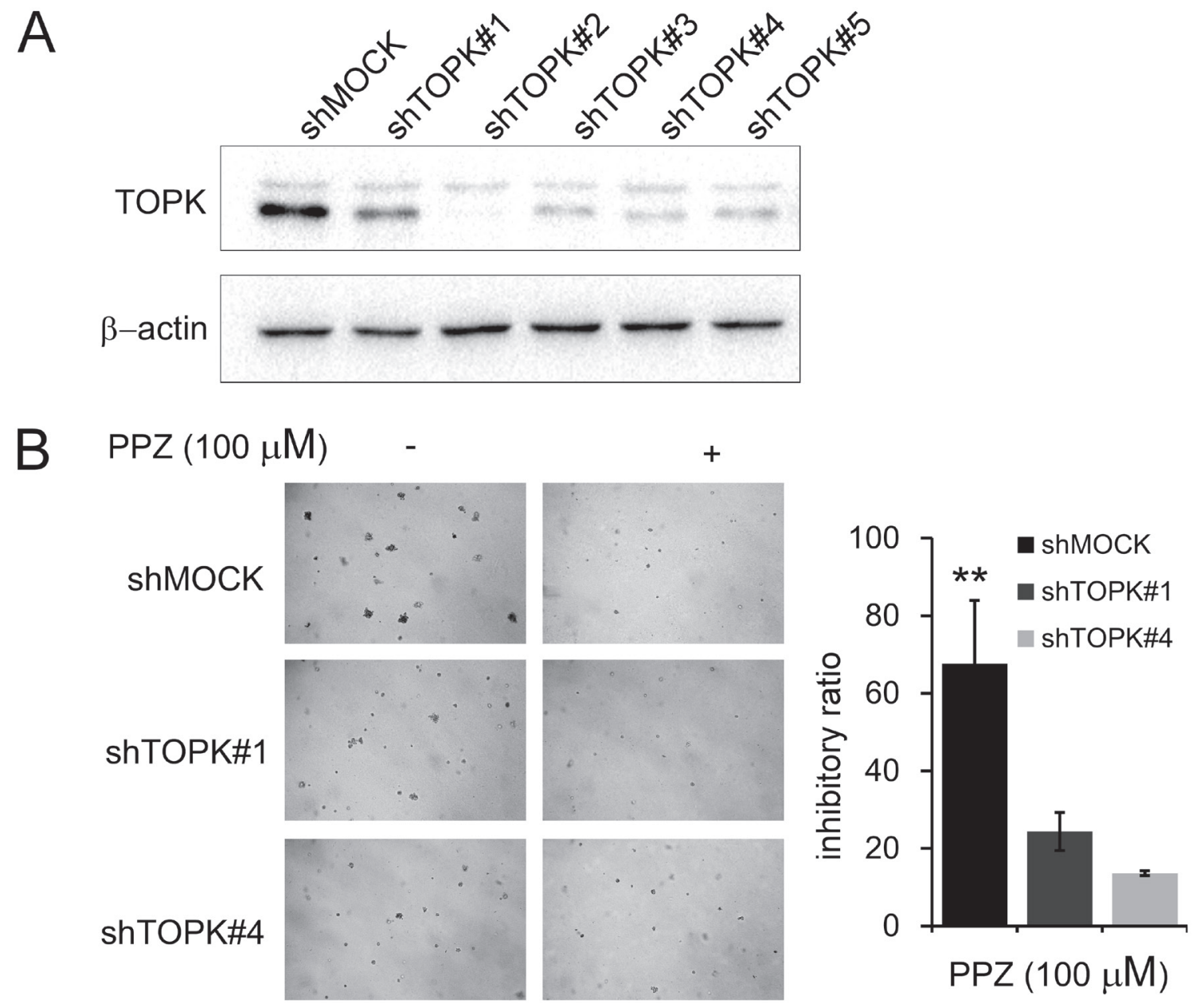

C

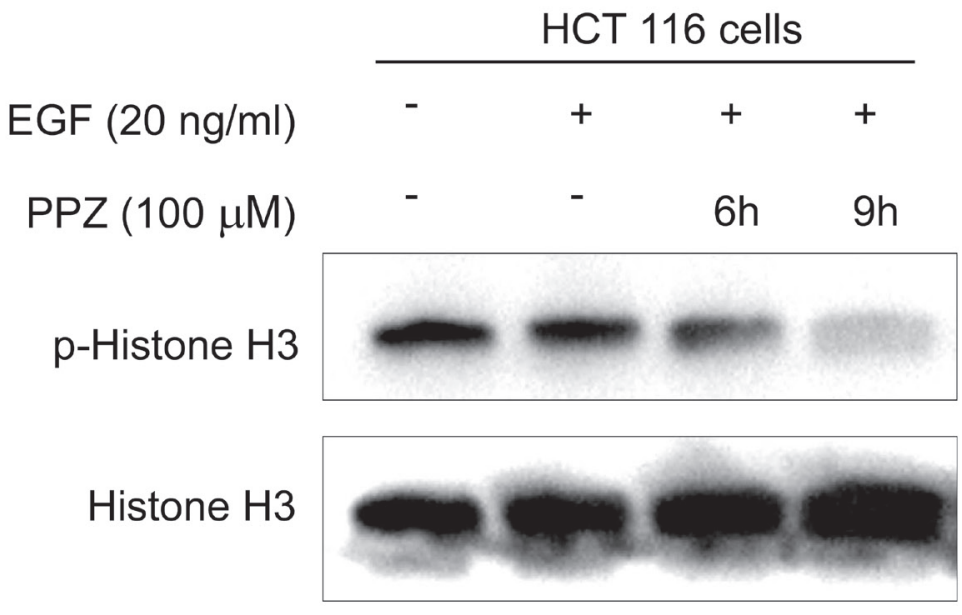

Figure 5: Knocking down TOPK attenuates the inhibitory effect of colon cancer cell growth by pantoprazole. A. Expression level of TOPK in HCT116 cells is decreased by knockdown of TOPK. HCT116 cells were transiently transfected with shMOCK or shTOPK (\#1-\#5) and cell lysates were analyzed by western blot. B. TOPK has less effect on anchorage-independent cell growth of shTOPK transfected cells than that of shMOCK cells. HCT116 cells were grown in soft agar with pantoprazole $(100 \mu \mathrm{M})$ for 10 days and the colonies were counted. Data are represented as mean \pm standard deviation from triplicate experiments. The asterisks $(* *)$ indicate a significant decrease compared with shMOCK cells $(P<0.01)$. C. Pantoprazole inhibits TOPK activity in HCT 116 cells. After HCT116 cells $\left(2 \times 10^{6}\right)$ were cultured in a $10-\mathrm{cm}$ dish for $24 \mathrm{~h}$, the cells were starved in serum-free medium for another $24 \mathrm{~h}$, in the meantime the cells were treated with pantoprazole $(100 \mu \mathrm{M})$ for $(0-12 \mathrm{~h})$, then treated with EGF $(80 \mathrm{ng} / \mathrm{ml})$ for $15 \mathrm{~min}$. The cells were then harvested and the protein levels were determined by western blot analysis using specific antibodies. Data are representatives of results from triplicate experiments. 
A

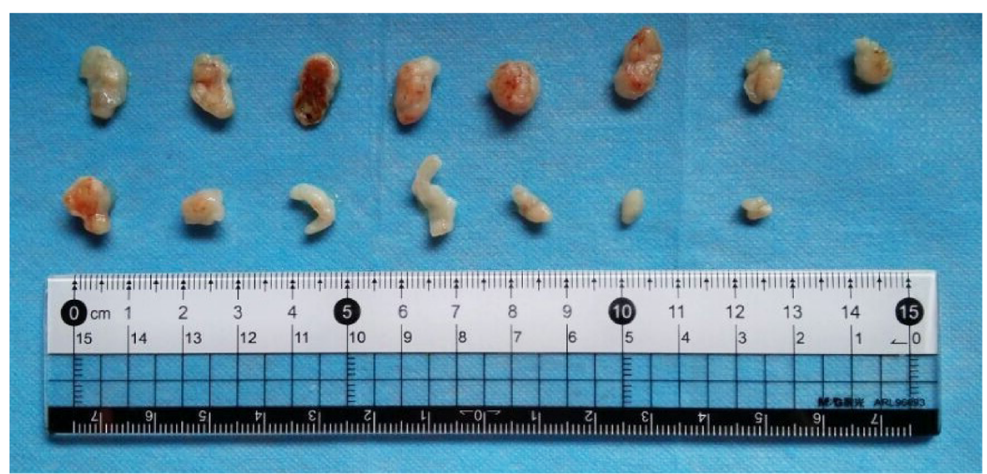

vehicle control

PPZ 100mg/kg

B
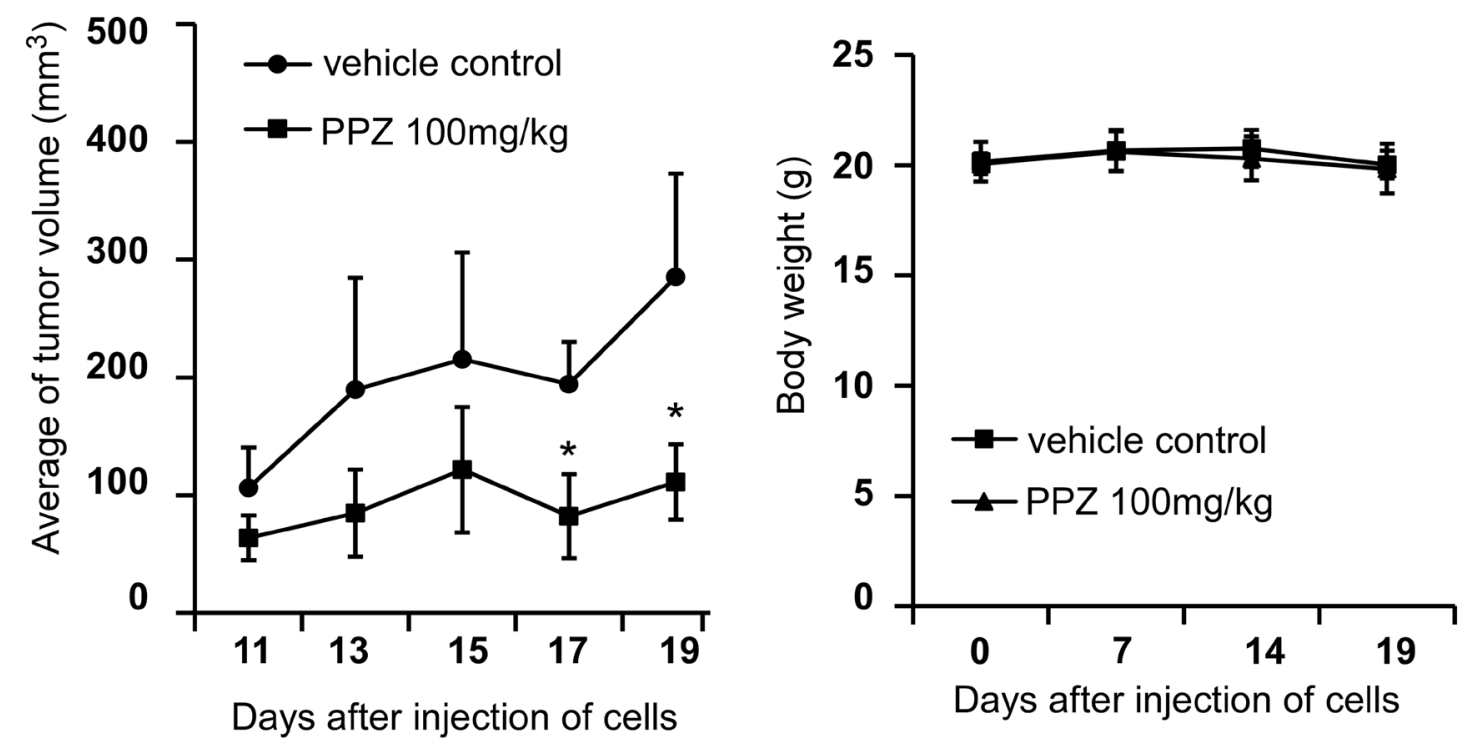

Days after injection of cells

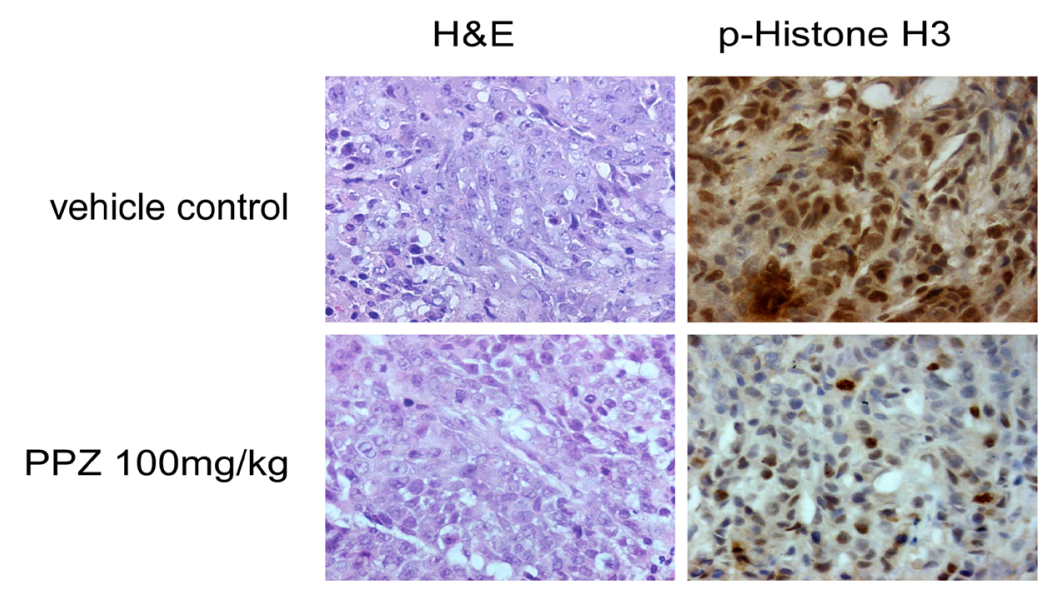

Figure 6: Pantoprazole suppresses tumor growth by inhibiting TOPK activity in vivo. A. Pantoprazole significantly suppresses cancer growth in a HCT116 xenograft mouse model. B. The average tumor volume of vehicle-treated control mice $(\mathrm{n}=8)$ and pantoprazole treated mice $(\mathrm{n}=8)$ plotted over 20 days after tumor cell injection. The asterisk $\left({ }^{*}\right)$ indicates a significant increased tumor size $(P<0.05)$ in the vehicle-treated group compared with that in the pantoprzole-treated group as determined by one-way analysis of variance. C. Pantoprazole has no effect on mouse body weight. Body weights from the treated or untreated groups of mice were measured once a week. D. Pantoprazole inhibits expression of phosphorylated histone $\mathrm{H} 3$ in vivo. Immunohistochemistry analysis was used to determine the level of phosphorylated histone $\mathrm{H} 3$ in tumor tissues. 
Pantoprazole is a standard treatment for gastric acid-related diseases and Helicobacter pylori infection together with antibiotics [23]. Besides targeting the gastric acid pump, PPIs inhibit activities of V-ATPase [24]. Recent studies reported that the pretreatment of PPIs increased sensitivities of drug-resistant cancer cells to cytotoxic drugs, such as melanomas [25], lymphomas [26] and gastric adenocarcinomas [27, 28]. There are also some data providing the proof of the concept that PPIs may be used as antineoplastic agents, but the underlying mechanisms is far from conclusive. Pantoprazole as a proton-pump inhibitor, is a prodrug, which requires protonation for functional activation under acidic conditions, accumulated selectively in acidic gastric luminal space, and ultimately inhibits acid secretion by covalently binding to cysteine residues in $\alpha$-subunit of $\mathrm{H}^{+} / \mathrm{K}^{+}$-ATPase [29-30]. However, in this study, cells were treated in medium with $\mathrm{pH}$ 7.2-7.4, not in acid condition. It is strongly implied that pantoprazole inhibits tumor growth by its prodrug form.

Previous studies showed that TOPK was a novel serine-threonine kinase that was a member of MAPKK family. TOPK was involved in many cellular functions, including tumor development, cell growth, apoptosis, and inflammation [31-33]. During mitosis, kinase activities of TOPK is elevated, and TOPK promotes phosphorylation of histone $\mathrm{H} 3, \mathrm{PRC} 1$ (protein regulator of cytokinesis 1), GPSM2 [G protein (heterotrimeric guanine nucleotidebinding protein) signaling modulator 2], and p97 proteins that are essential for the completion of cancer cell cytokinesis [34-36]. Therefore, it is likely that TOPK phosphorylates various protein substrates that are essential for cancer cell survival and proliferation, particularly in the mitotic phase of cell cycle.

Consistent with reported studies, our results indicated that the phosphorylation of histone H3 (Ser10) in vitro and in vivo were both strongly reduced by pantoprazole (Figure 3A-3C, Figure 5C). Notably, the phosphorylation of histone $\mathrm{H} 3$ (Ser10) was inhibited in vivo in pantoprazole-treated tumor tissues (Figure 6D).

In conclusion, we provided evidences showing that pantoprazole effectively suppressed anchorageindependent cell growth of colon cancer cells with high expressed TOPK levels, and suppressed in vivo tumor growth of HCT 116 cells by inhibiting TOPK activities. Overall, our findings offer an alternative therapy for colorectal cancer by targeting TOPK with pantoprazole.

\section{MATERIALS AND METHODS}

\section{Reagents and antibodies}

Pantoprazole sodium for injection was purchased from Hangzhou Zhongmei Huadong Pharmaceutical Co., Ltd (China). MTS (3-(4,5-dimethylthiazol-2-yl)5-(3-carboxymethoxyphenyl)-2H-tetrazdium) assay kit was purchased from "Promega" (USA). Antibodies against phospho-Histone H3, TOPK/PBK, Histone H3, were obtained from "Cell Signaling Technology" (USA), $\beta$-actin and horseradish peroxidase (HRP) conjugated secondary antibody from rabbit and mouse were purchased from "Santa Cruz" (USA) and "Protein Tech Group" (USA), respectively. The chemiluminescence's detection kit ECL Plus was from "GE Healthcare" (USA). The Basal Medium Eagle (BME), Dulbecco's Modified Eagle medium (DMEM), Minimum Essential medium (MEM), McCoy's 5A Modified medium (McCoy's 5A), Roswell Park Memorial Institute medium (RPMI 1640), phosphate buffered saline (PBS), L-glutamine, gentamicin solution, trypsin, fetal bovine serum (FBS), sodium hydrocarbonate $\left(\mathrm{NaHCO}_{3}\right)$, and agar were purchased from "Sigma" and "Gibco" (USA). All other common chemicals, solvents and reagents were of highest grade available from various commercial sources.

\section{Cell lines and culture conditions}

Mouse epidermal JB6 Cl41 cells (ATCC \# CRL2010) and human colon cancer cells HCT 116(ATCC \# CCL-247TM), SW480 (ATCC \# CCL-228 ${ }^{\mathrm{TM}}$ ), WiDr (ATCC \# CCL-218 ${ }^{\mathrm{TM}}$ ) were obtained from the American Type Culture Collection (ATCC, USA). Mouse epidermal JB6 C141, human colon cancer HCT 116, SW480, and WiDr cells were cultured in MEM/ $5 \%$ FBS, McCoy's 5 A/10\% FBS, RPMI-1640/10\% FBS and RPMI-1640/10\% FBS media, respectively. The cell cultures were maintained at $37^{\circ} \mathrm{C}$ in humidified atmosphere containing $5 \% \mathrm{CO}_{2}$. The cells were grown for 3-4 days, and after reaching $90 \%$ of confluence they were harvested by exposure to $0.25 \%$ Trypsin-EDTA or $0.25 \%$ Trypsin without EDTA (JB6 C141) solution and then passed into new T-75 tissue culture flasks. The cell cultures were performed following the instructions of ATCC.

\section{Microscale thermophoresis (MST)}

Recombinant TOPK was labeled with the Monolith NT ${ }^{\text {TM }}$ Protein Labeling Kit RED (Cat\#L001) according to the supplied labeling protocol. Labeled TOPK was used in a concentration of $50 \mathrm{nM}$. The samples were diluted in a $20 \mathrm{mM}$ HEPES (pH 7.4) and 0.05 (v/v) \% Tween-20. The pantoprazole stock was dissolved in $\mathrm{ddH}_{2} \mathrm{O}$ in a concentration of $5 \mathrm{mM}$. We used $5 \mathrm{mM}$ pantoprazole as the highest concentration for the serial dilution. After 10 minutes incubation at room temperature the samples were loaded into MonolithTM standard-treated capillaries and the thermophoresis was measured at $25^{\circ} \mathrm{C}$ after 30 minutes incubation on a Monolith NT.115 instrument (NanoTemper Technologies, München, Germany). Laser power was set to $20 \%$ or $40 \%$ using 30 seconds on-time. The LED power was set to $100 \%$. The dissociation constant Kd values were fitted by using the NTAnalysis software (NanoTemper Technologies, München, Germany) [37]. 


\section{Homology modeling and molecular docking}

With the crystal structure of the IRAK-4 kinase (PDB code: 2NRU) as the template, a homology model of human TOPK (accession number: NP 060962) was constructed by using MODELLER (an automated homology modeling program) [38-39]. The subset zdd (ZINC Drug Database), which included all commercially available approved drugs and nutraceuticals worldwide, was downloaded from ZINC as mol2 files, which were used as input for docking [40]. The docking was performed by using ICM 3.8.1 modeling software on an Intel i7 4960 processor (MolSoft LLC, San Diego, CA) [41]. Ligand binding pocket residues were selected by using graphical tools in the ICM software, to create the boundaries of the docking search. In the docking calculation, potential energy maps of the receptor were calculated using default parameters. The compounds were imported into ICM and an index file was created. The conformational sampling was based on the Monte Carlo procedure, and finally the lowest-energy and the most favorable orientation of the ligand was selected.

\section{MTS assay}

To estimate cell viability, mouse epidermal JB6 Cl41, human colon cancer HCT 116, SW480, and WiDr cells $(1000 /$ well) were seeded in 96-well plates for $24 \mathrm{~h}$ at $37^{\circ} \mathrm{C}$ in a $5 \% \mathrm{CO}_{2}$ incubator. The attached cells were fed with fresh medium containing various concentrations of pantoprazole $(0-100 \mu \mathrm{M})$ for additional $24 \mathrm{~h}$ and 48 h. After culturing for various times, the cytotoxicity of pantoprazole was measured using an MTS assay kit according to the manufacturer's instructions. All the experiments were performed in triplicate, and the mean absorbance values were calculated. The results are expressed as the percentage of inhibition that produced a reduction in absorbance by pantoprazole treatment compared with the non-treated cells (control).

\section{Anchorage-independent cells transformation assay (Soft agar)}

Mouse epidermal JB6 C141 cells $\left(2.4 \times 10^{4}\right)$ were exposed to EGF $(20 \mathrm{ng} / \mathrm{ml})$ and treated with pantoprazole $(0-100 \mu \mathrm{M})$ in $1 \mathrm{~mL}$ of $0.3 \%$ Basal Medium Eagle (BME) agar containing $10 \% \mathrm{FBS}, 2 \mathrm{mM}$ L-glutamine, and $25 \mu \mathrm{g} /$ $\mathrm{mL}$ gentamicin. The cultures were maintained at $37^{\circ} \mathrm{C}$, in a 5\% $\mathrm{CO}_{2}$ incubator for 7-14 days, and the cell's colonies were scored using a microscope Motic AE 20 (China) and the Motic Image Plus computer program. To estimate the effect of pantoprazole on colony formation, colon cancer cells HCT 116, SW480, and WiDr $\left(2.4 \times 10^{4}\right)$ were treated with pantoprazole $(0-100 \mu \mathrm{M})$ in $1 \mathrm{~mL}$ of $0.3 \%$ Basal Medium Eagle (BME) agar containing 10\% FBS, 2 mM $\mathrm{L}$-glutamine, and $25 \mu \mathrm{g} / \mathrm{ml}$ gentamicin. The cultures were maintained in a $37^{\circ} \mathrm{C}, 5 \% \mathrm{CO}_{2}$ incubator for 7-14 days, and the cell colonies were scored as described above.

\section{In vitro kinase assay}

Inactive histone $\mathrm{H} 3$ proteins were used as the substrate for an in vitro kinase assay with active TOPK. Firstly, active TOPK was incubated with pantoprazole $(50$ and $100 \mu \mathrm{M})$ in $1 \times$ kinase buffer $(25 \mathrm{mM}$ Tris- $\mathrm{HCl}$ $\mathrm{pH}$ 7.5, $5 \mathrm{mM}$ b-glycerophosphate, $2 \mathrm{mM}$ dithiothreitol (DTT), $0.1 \mathrm{mM} \mathrm{Na}_{3} \mathrm{VO}_{4}, 10 \mathrm{mM} \mathrm{MgCl}$, and $5 \mathrm{mM}$ $\mathrm{MnCl}_{2}$ ) at $32^{\circ} \mathrm{C}$ for 15 minutes. Then inactive histone $\mathrm{H} 3$ and $100 \mu \mathrm{M}$ ATP were added to reaction and incubated at $32^{\circ} \mathrm{C}$ for $1.5 \mathrm{~h}$. Reactions were stopped by adding $5 \times$ SDS sample buffer and then were analyzed by Western blot.

\section{Western blot analysis}

The harvested cells were lysed with lysis buffer (50 mM Tris-HCl (pH 7.4), $150 \mathrm{mM} \mathrm{NaCl}, 1 \mathrm{mM}$ EDTA, $1 \mathrm{mM}$ EGTA, $10 \mathrm{mg} / \mathrm{mL}$ aprotinin, $10 \mathrm{mg} / \mathrm{mL}$ leupeptin, $5 \mathrm{mM}$ phenylmethanesulfonyluoride (PMSF), $1 \mathrm{mM}$ dithiolthreitol (DTT) containing 1\% Triton X-100). Insoluble debris was removed by centrifugation at 12000 rpm for 15 minutes, and protein's content was determined using Bradford reagent (Bio-Rad, USA). Lysate protein $(20-40 \mu \mathrm{g})$ was subjected to $10 \%$ SDS-PAGE and electrophoretically transferred to polyvinylidene difluoride membranes (PVDF) (Millipore, USA). The membranes were blocked with 5\% non-fat milk or 5\% BSA for $1 \mathrm{~h}$ and then incubated with the respective specific primary antibody at $4^{\circ} \mathrm{Covernight}$. Protein bands were visualized using an enhanced chemiluminescence reagent (ECL Plus) (GE Healthcare, USA) after hybridization with a HRP conjugated secondary antibody. Band density was quantified using the Image J software program (NIH).

\section{Isolation of histone $\mathrm{H3}$}

Histones were extracted from cells by disrupting the cells with NETN buffer [150 mM NaCl, 1 mM EDTA, 20 $\mathrm{mM}$ Tris- $\mathrm{HCl}(\mathrm{pH} 8.0), 0.5 \%$ nonionic detergent IGEPAL CA 630(NP-40), Sigma]. The insoluble fraction was pelleted for 5 minutes in a microcentrifuge $(8,400 \mathrm{rpm})$. Nuclei were extracted with $0.1 \mathrm{M} \mathrm{HCl}$ to isolate the total histones. The samples were precipitated with $1 \mathrm{M}$ Tris$\mathrm{HCl}(\mathrm{pH} 8.0)$ and then resuspended in $\mathrm{ddH}_{2} \mathrm{O}$.

\section{In vivo xenograft mouse model}

Non-obese Diabetic/Severe Combined Immunodeficiency (NOD-SCID) mice were purchased from Beijing HFK Bioscience CO., LTD (Beijing, China). The animals were maintained under 'specific pathogenfree' conditions according to the guidelines established by Research Animal Resources, Laboratory Animal 
Center, The Fourth Military Medical University (China). The mice were randomly divided into two groups: (i) vehicle group ( $\mathrm{n}=8$ ); (ii) $100 \mathrm{mg} / \mathrm{kg}$ pantoprazole-treated group $(n=8)$. The experiment was repeated with HCT 116 colon cancer cells. HCT 116 cells were inoculated subcutaneously $\left(5 \times 10^{6}\right.$ cells $)$ into the left flank of each mouse in the two groups. Treatment was started after two days of cells injection. For the pantoprazole group, $2.5 \mathrm{mg}$ pantoprazole, formulated in $200 \mu \mathrm{l}$ physiological saline, was administered to each mouse every two days by intraperitoneal (i.p.) injection. For the vehicle group, 200 $\mu \mathrm{l}$ physiological saline was administered to each mouse every two days by i.p. injection. The duration of the animal study was 19 days for HCT 116 cells. The tumor volume was calculated from measurements of 3 diameters of the individual tumor based on the following formula: tumor volume $\left(\mathrm{mm}^{3}\right)=($ length $\times$ width $\times$ height $\times 0.52)$. The mice were monitored until tumors reached $1 \mathrm{~cm}^{3}$ total volume, at which time the mice were euthanized and the tumors were extracted. The tumors were dissected and sent for immunohistochemical analysis at the Department of Pathology in Xijing Hospital (The Fourth Military Medical University, China). All animal experiments were performed following the protocols approved by the Laboratory Animal Center of the Fourth Military Medical University.

\section{CONFLICTS OF INTEREST}

No conflicts of interest.

\section{GRANT SUPPORT}

This project was supported by grants from the national Natural Science Foundation of China (No. $81472602,81450110449 \& 30271302)$, the Independent innovation project of Huazhong University of Science and Technology (No. 2014TS063, 2015650011 \& 2014ZZGH013), and the Natural Science Foundation of Hubei Province (No. 2014CFB447).

\section{REFERENCES}

1. Collins I, Workman P. New approaches to molecular cancer therapeutics. Nat Chem Biol. 2006; 2:689-700. doi: 10.1038/nchembio840

2. Capdeville R, Buchdunger E, Zimmerman J, Matter A. Glivec (STI571), a rationally developed, targeted anticancer drug. Nat Rev Drug Discov. 2002; 1:493. doi: 10.1038/ $\operatorname{nrd} 839$

3. Zhu F, Zykova TA, Kang BS, Wang Z, Ebeling MC, Abe Y, Ma WY, Bode AM, Dong Z. Bidirectional signals transduced by TOPK-ERK interaction increase tumorigenesis of HCT 116 colorectal cancer cells. Gastroenterology. 2007; 133:219-31. doi: 10.1053/j. gastro.2007.04.048
4. Abe Y, Matsumoto S, Kito K, Ueda N. Cloning and expression of a novel MAPKK-like protein kinase, lymphokine-activated killer T-cell-originated protein kinase, specifically expressed in the testis and activated lymphoid cells. J Biol Chem. 2000; 275:21525-31. doi: 10.1074/jbc.m909629199

5. He F, Yan Q, Fan L, Liu Y, Cui J, Wang J, Wang L, Wang Y, Wang Z, Guo Y, Huang G. PBK/TOPK in the differential diagnosis of cholangiocarcinoma from hepatocellular carcinoma and its involvement in prognosis of human cholangiocarcinoma. Hum Pathol. 2010; 41:41524. doi: 10.1016/j.humpath.2009.05.016

6. Nandi A, Tidwell M, Karp J, Rapoport AP. Protein expression of PDZ-binding kinase is up-regulated in hematologic malignancies and strongly downregulated during terminal differentiation of HL-60 leukemic cells. Blood Cell Mol Dis. 2004; 32:240-245. doi: 10.1016/j. bcmd.2003.10.004

7. Ryu B, Kim DS, Deluca AM, Alani RM. Comprehensive expression profiling of tumor cell lines identifies molecular signatures of melanoma progression. PLoS One. 2007; 2:e594. doi: 10.1371/journal.pone.0000594

8. Zlobec I, Molinari F, Kovac M, Bihl MP, Altermatt HJ, Diebold J, Frick H, Germer M, Horcic M, Montani M, Singer G, Yurtsever H, Zettl A, et al. Prognostic and predictive value of TOPK stratified by KRAS and BRAF gene alterations in sporadic, hereditary and metastatic colorectal cancer patients. Brit J Cancer. 2010; 102:151161. doi: 10.1038/sj.bjc.6605452

9. Albino D, Scaruffi P, Moretti S, Coco S, Truini M, Di Cristofano C, Cavazzana A, Stigliani S, Bonassi S, Tonini GP. Identification of low intratumoral gene expression heterogeneity in neuroblastic tumors by genome wide expression analysis and game theory. Cancer. 2008; 113:1412-1422. doi: 10.1002/cncr.23720

10. Wuttig D, Baier B, Fuessel S, Meinhardt M, Herr A, Hoefling C, Toma M, Grimm MO, Meye A, Rolle A, Wirth MP. Gene signatures of pulmonary metastases of renal cell carcinoma reflect the disease-free interval and the number of metastases per patient. Int J cancer. 2009; 125:474-482. doi: 10.1002/ijc.24353

11. Park JH, Nishidate $T$, Nakamura $Y$, Katagiri $T$. Critical roles of T-LAK cell-originated protein kinase in cytokinesis. Cancer Sci. 2010; 101:403-11. doi: 10.1111/j.1349-7006.2009.01400.x

12. Simons-Evelyn M, Bailey-Dell K, Toretsky JA, Ross DD, Fenton R, Kalvakolanu D, Rapoport AP. PBK/TOPK is a novel mitotic kinase which is upregulated in Burkitt's lymphoma and other highly proliferative malignant cells. Blood Cells Mol Dis. 2001; 27:825-9. doi: 10.1006/ bcmd.2001.0452

13. Oh SM, Zhu F, Cho YY, Lee KW, Kang BS, Kim HG, Zykova TA, Bode AM, Dong Z. T-lymphokine-activated killer cell-originated protein kinase functions as a positive regulator of c-Jun-NH2-kinase 1 signaling and 
H-Ras-induced cell transformation. Cancer Res. 2007; 67:5186-94. doi: 10.1158/0008-5472.can-06-4506

14. Kim DJ, Li Y, Reddy K. Novel TOPK inhibitor HI-TOPK-032 effectively suppresses colon cancer growth. Cancer Res. 2012; 72:3060-8. doi: 10.1158/0008-5472. can-11-3851

15. Yo Matsuo. TOPK inhibitor induces complete tumor regression in xenograft models of human cancer through inhibition of cytokinesis. Science Translational Medicine. 2014; 6:259ra145. doi: 10.1126/scitranslmed.3010277

16. Zlobec I, Molinari F, Kovac M, Bihl MP, Altermatt HJ, Diebold J, Frick H, Germer M, Horcic M, Montani M, Singer G, Yurtsever H, Zettl A. Prognostic and predictive value of TOPK stratified by KRAS and BRAF gene alterations in sporadic, hereditary and metastatic colorectal cancer patients. Br J Cancer. 2010; 102:151-61. doi: 10.1038/sj.bjc. 6605452

17. Tobinick, E.L. The value of drug repositioning in the current pharmaceutical market. Drug News Perspect. 2009; 22:119-125. doi: 10.1358/dnp.2009.22.2.1303818

18. Kridel SJ, Axelrod F, Rozenkrantz N, Smith JW. Orlistat is a novel inhibitor of fatty acid synthase with antitumor activity. Cancer Res. 2004; 64:2070-2075. doi: 10.1158/0008-5472.can-03-3645

19. Chan DS, Lee HM, Yang F, Che CM, Wong CC, Abagyan $\mathrm{R}$, Leung $\mathrm{CH}$, Ma DL. Structure-Based Discovery of Natural-Product-like TNF- $\alpha$ inhibitors. Angew Chem Int Ed. 2010; 49:2860 -2864. doi: 10.1002/anie.200907360

20. Liu H, Gao ZB, Yao Z, Zheng S, Li Y, Zhu W, Tan X, Luo X, Shen J, Chen K, Hu GY, Jiang H. Discovering potassium channel blockers from synthetic compound database by using structure-based virtual screening in conjunction with electrophysiological assay. J Med Chem. 2007; 50:83-93. doi: $10.1021 / \mathrm{jm} 060414 \mathrm{o}$

21. Choi H, Lee Y, Park H, Oh DS. Discovery of the inhibitors of tumor necrosis factor alpha with structure-based virtual screening. Bioorganic \& Medicinal Chemistry. 2010; 20:6195-6198. doi: 10.1016/j.bmcl.2010.08.116

22. Lagos CF, Vecchiola A, Allende F, Fuentes CA, Tichauer JE, Valdivia C, Solari S, Campino C, Tapia-Castillo A, Baudrand R, Villarroel P, Cifuentes M, Owen GI, et al. Identification of novel 11 $\beta$-HSD1 inhibitors by combined ligand- and structure-based virtual screening. Mol Cell Endocrinol. 2014; 384:71-82. doi: 10.1016/j. mce.2014.01.011

23. Boparai V, Rajagopalan J, Triadafilopoulos G. Guide to the use of proton pump inhibitors in adult patients. Drugs. 2008; 68:925-47. doi: 10.2165/00003495-200868070-00004

24. Moriyama Y, Patel V, Ueda I, Futai M. Evidence for a common binding-site for omeprazole and $\mathrm{N}$-ethylmaleimide in subunit A of chromaffin granule vacuolar-typeH+ATPase. Biochem Biophys Res Commun. 1993; 196:699706. doi: 10.1006/bbrc.1993.2306
25. Luciani F, Spada M, De Milito A, Molinari A, Rivoltini L, Montinaro A, Marra M, Lugini L, Logozzi M, Lozupone F, Federici C, Iessi E, Parmiani G, et al. Effect of proton pump inhibitor pretreatment on resistance of solid tumors to cytotoxic drugs. J Natl Cancer Inst. 2004; 96:1702-13. doi: 10.1093/jnci/djh305

26. De Milito A, Iessi E, Logozzi M, Lozupone F, Spada M, Marino ML, Federici C, Perdicchio M, Matarrese P, Lugini L, Nilsson A, Fais S. Proton pump inhibitors induce apoptosis of human B-cell tumors through a caspaseindependent mechanism involving reactive oxygen species. Cancer Res. 2007; 67:5408. doi: 10.1158/0008-5472. can-06-4095

27. Chen M, Zou X, Luo H, Cao J, Zhang X, Zhang B, Liu W. Effects and mechanisms of proton pump inhibitors as a novel chemosensitizer on human gastric adenocarcinoma (SGC7901) cells. Cell Biol Int. 2009; 33:1008-19. doi: 10.1016/j.cellbi.2009.05.004

28. Chen M, Huang SL, Zhang XQ, Zhang B, Zhu H, Yang VW, Zou XP. Reversal effects of pantoprazole on multidrug resistance in human gastric adenocarcinoma cells by downregulating the $\mathrm{V}$-ATPases/mTOR/HIF-1 $\alpha / \mathrm{P}$-gp and MRP1 signaling pathway in vitro and in vivo. $\mathrm{J}$ Cell Biochem. 2012; 113:2474-87. doi: 10.1002/jcb.24122

29. Sachs G1, Shin JM, Briving C, Wallmark B, Hersey S. The pharmacology of the gastric acid pump: the $\mathrm{H}+$, K+-ATPase. Ann Rev Pharmacol Toxicol. 1995; 35:277305. doi: 10.1146/annurev.pharmtox.35.1.277

30. Horn J. The proton-pump inhibitors: similarities and differences. Clin Ther. 2000; 22:266 -80. doi: 10.1016/ s0149-2918(00)80032-6

31. Zhu F, Zykova TA, Kang BS, Wang Z, Ebeling MC, Abe Y, Ma WY, Bode AM, Dong Z. Bidirectional signals transduced by TOPK-ERK interaction increase tumorigenesis of HCT 116 colorectal cancer cells. Gastroenterology. 2007; 133:219-31. doi: 10.1016/ s0149-2918(00)80032-6

32. Ayllon $\mathrm{V}, \mathrm{O}^{\prime}$ Connor R. PBK/TOPK promotes tumour cell proliferation through p38 MAPK activity and regulation of the DNA damage response. Oncogene. 2007; 26:3451-61. doi: 10.1038/sj.onc. 1210142

33. Hu F, Gartenhaus RB, Eichberg D, Liu Z, Fang HB, Rapoport AP. PBK/TOPK interacts with the DBD domain of tumor suppressor p53 and modulates expression of transcriptional targets including p21. Oncogene. 2010; 29:5464-74. doi: 10.1038/onc.2010.275

34. Park JH, Nishidate $T$, Nakamura $Y$, Katagiri $T$. Critical roles of T-LAK cell-originated protein kinase in cytokinesis. Cancer Sci. 2010; 101:403-411. doi: 10.1111/j.1349-7006.2009.01400.x

35. Abe Y, Takeuchi T, Kagawa-Miki L, Ueda N, Shigemoto $\mathrm{K}$, Yasukawa M, Kito K. A mitotic kinase TOPK enhances Cdk1/cyclin B1-dependent phosphorylation of PRC1 and 
promotes cytokinesis. J. Mol. Biol. 2007; 370:231-245. doi: 10.1016/j.jmb.2007.04.067

36. Fukukawa C, Ueda K, Nishidate T, Katagiri T, Nakamura Y Critical roles of LGN/GPSM2phosphorylation by PBK/TOPK in cell division of breast cancer cells. Genes ChromosomesCancer. 2010; 49:861-872. doi: 10.1016/j. jmb.2007.04.067

37. Wienken, C. J, Baaske, P, Rothbauer, U, Braun, D, Duhr, S. Protein-binding assays in biological liquids using microscale thermophoresis. Nat. Commun. 2010; 1:100. doi: 10.1038/ncomms1093

38. Fiser A, Sali A. "Modeller: generation and refinement of homology-based protein structure models". Meth. Enzymol. 2003; 374:461-91. doi: 10.1038/ncomms1093
39. Kirubakaran P, Karthikeyan M, Singh KhD, Nagamani S, Premkumar K. In silico structural and functional analysis of the human TOPK protein by structure modeling and molecular dynamics studies. J Mol Model. 2013; 19:40719. doi: $10.1007 / \mathrm{s} 00894-012-1566-1$

40. Irwin, Sterling, Mysinger, Bolstad and Coleman. ZINC: A Free Tool to Discover Chemistry for Biology. J Chem Inf Model. 2012; 52:1757-1768. doi: 10.1021/ci3001277

41. Abagyan R, Totrov M, Kuznetsov D. ICM-A new Method for Protein Modeling and Design: applications to Docking and Structure Prediction from the Distorted Native Conformation. Journal of Computational Chemistry. 1994; 15:488-506. doi: 10.1002/jcc.540150503 